\title{
Research Status and Prospect of the Quantitative Description on the Roof Fissure Zone
}

\author{
Zhang Bichuan $^{1,2,3^{*}}$, Dai Linchao ${ }^{1,2}$, Sun Dongling ${ }^{1,2}$, Yang Huiming ${ }^{1,2}$ \\ ${ }^{1}$ State Key Laboratory of The Gas Disaster Detecting, Preventing and Emergency Controlling, \\ Chongqing 400037, China; \\ ${ }^{2}$ Gas Research Branch, China Coal Technology and Engineering Group Chongqing Research \\ Institute, Chongqing 400037, China; \\ ${ }^{3}$ China Coal Research Institute, Beijing 100013, China. \\ *Email: 1287651036@qq.com
}

\begin{abstract}
In order to quantify the damage degree of fissure zone coal seams, research findings of quantitative description of fissure zone in China were presented in the paper, different opinions and methods of research on quantitative description of fissure zones were expounded, so were the processes of development. Existing research findings on quantitative description of fissure zone were analysed. Currently, research on quantitative description of fissure zones has developed from semi-quantitative to quantitative and the evolution of the fracture field is closely related to the seepage field and stress field received wide acceptance. The future of quantitative description of fissure zone was discussed.
\end{abstract}

Keywords: Fissure zone; Methane extraction; Quantitative description of fracture; Range of fissure zone; Overburden.

\section{Introduction}

The growing mining strength and deepening mining depth can increase the content and emission rate of methane gas within in coal mines. Gas over-limit has become a key issue that reject the efficiency of intensified coal mining. It is important to achieve the coal and gas simultaneous extraction that apply the evolution rule of mining induced fissure to the gas extraction [1]. Methane gas is commonly known as a relatively clean energy. Considering the huge amount of gas resources in China, gas energy will play a core role in the future energy consumptions. The low permeability and high adsorption of coal seam in China determines that to extract the gas effectively, the coal seam must be decompressed so that the permeability can increase. Only after the decompression, the gas extraction in the fissure zone can be practicable. The efficiency of gas extraction in fissure zone is determined by many factors including the hole diameter, hole distribution and negative extract pressure. The critical factors are the hole distribution and dimension, to decide those two factors, the quantitative description on the fissure zone of overburden rock under mining condition must be processed.

In the recent years, researchers among the world have used methods based on the theoretical knowledges including numerical simulation, physical modelling and experiments to study on the range and evolution mechanism of fissure zone and have accomplished remarkable results[1-9]. In China, researchers found the factors that may affect the possible develop height of fissure zone based on masonry beam theory, "O" circle theory and double fractal dimension methods. Thus, they established using drilling-combine exploration to report the fissure development. They found the possibilities for the gas extraction in the fissure zones. However, the permeability of fissure zones can be widely changed due to the high density and high connectivity of mining induced fissure, and the analysis of gas extraction in fissure zone can be massively affected. The procedure of formation, development and connection of mining induced fissures can be affected by many factors so that the development of fissure zone is a complicated process. Therefore, it is critical to tease the basic 
theories and quantitative descriptions of fissure zones. They are important references for the roof long hole drilling, high position alley pumping selection and surface gas extract location selection.

\section{Research Status in China}

In China, the researches on the coal seam roof pressure control, roof broken conditions, roof fissure development and water diversion fissure height began at 1950s. From the current information and relevant experiments results, researchers also discussed on the quantitative description of fissure zones. In the most recent times, many new knowledges and theories has established based on new methods and tools.

Researchers and Theories. Chinese coal safety and geology researchers put heavy efforts on the coal seam roof fissure zones and quantitative descriptions, the names and their theories as follow:

Minggao Qian [1,9] considered that firm roof can be seen as beam or board before its rock layer broken. After the rock broken, the nubby rock structure can be formed as blocked structure. Based on the rock layer movement, Qian introduced typical blocked structure type called "Horizontal Three" and "Vertical Three". "Vertical Three" fissure zones can carry massive gas with high concentration, it is an ideal area for gas extraction or decompression for surrounding layers.

Tianquan Liu [10] ran massive statistic analysis on the fissure zones development of many coal mines, and figured out an experimental formula for the water diversion fissure height. Liu also studied on the factors of water diversion fissure height development, thus he offered methods for determination of roof fissure zones lower limit height.

Jialin $\mathrm{Xu}[11,12,13,14]$ deemed that key strata movement can control the separated strata fissure formation, development and distribution. The overburden fissures can form the tunnel for gas transportation and is a key factor of its permeability. Before the first collapse of the key strata, the development of middle separated strata is stable and so it is a safe selection for the starting location of roof long hole drilling and high position alley pumping.

Qingxin Qi [15] used the methods of fractal dimensions of fissure numbers and area proportion to describe the development of fissure. He concluded that the numbers dimensions decrease and area proportion dimensions increase then the fissures would be connected; the numbers dimensions remain unchanged and area proportion dimensions increase then the fissures would be closed; numbers dimensions increase and area proportion dimensions decrease then new fissures would be formed and closed. This method clearly described the process of development of mining induced fissures and its relation to various mining conditions. However, by the effects of complicated geological factors, it is hard to gain the fractal dimensions of the geologic body.

Yujun Zhang etc. $[16,18]$ stated that the methods of prospection on the overburden rocks damage level mainly includes drilling, drilling geophysical prospecting and ground geophysical prospecting. For complicated geological conditions and different mining methods, the prospection ways now incorporate geophysical prospecting and drilling prospecting instead of obsolete single prospecting by the leakage of flushing liquid.

Researches in the Recent Years. Although there are no breakthrough results on the quantitative description of roof fissure zones due to the inhomogeneity and coupling, researchers have studied on the previous results and started new progress to develop the quantitative descriptions of roof fissure zones.

Hongyan Li etc. [19] divided the mining induced fissure fields into 4 regions by the simulation experiments, individually they are: low angle separated layer fissure zone, middle angle middle 
mine-out collapsed and fissure zone, high angle fissure expanding zone and mid-high transitional zone.

Haifei Lin etc. [20] found the factors that may affect the development of fissure zones by the simulation experiments. They concluded that the higher of mining height, the higher location that the fissure zone can reach on the key stratum; different overburden rock properties and structures can affect the fissure zone height; the higher of coal seam dip, the space height follow by the dip direction is more likely to be small bottom and large top; the length of the work face can control the maximum height of overburden fissure zone structures.

Wenxue Wang [21] built the model for the mine-out zone induced stress recovery. Based on the model and masonry beam theory, he concluded that vertical broken fissures are great in the surroundings of mine-out zone. However, within in the mine-out zone, vertical fissures close due to the induced stress recovery.

Min Tu [22] studied on the coupling mechanism of coal and rock deformation field, induced stress field and gas. Considering the gas seepage is non-Darcy, she concluded the gas movement features within in the fissure zones.

Jialin $\mathrm{Xu}$ [23] studied on the separate layer fissures of mining induced fissures. The height of separate layer fissure in a unit thickness of rock layer is presented by the abscission rate index. This method need to use the ratios between upper and lower rock layers sinkage differences and layer distance.

Wei Li etc. [24] used the two-value threshold method to the rock structure, thus separate the fissures and background. They also optimized the endpoint recognition algorithm, so that removed the veins within the fissures. A statistic of fissure length with high accuracy then has been performed.

Xijun Zhang etc. [16] observed the original fissure and mining induced fissure in the drilling holes by the colourcast system. They concluded that the original fissures are almost horizontal fissures. The mining induced fissures in the weaken rock layer can be crisscrossing, but in the hard rock layer the fissures are performed as highly developed, and getting lower angle as the distance between coal seam roof increases.

\section{Discussion on the current research results}

Quantitative description of roof fissure zones is now into quantitative development from the semiquantitative development. Masonry beam theories and "O" circle theories have gained common acceptance. Those theories can give theoretical support for the mining pressure control, accurately gas extraction point locating and high position alley pumping. Two discussions are contained in the quantitative description of roof fissure zone: the range of fissure zone and the overview of fissure zone. The range of fissure zone is affected by the key stratum height and gas flow fissure height. Therefore, to estimate the range of the fissure zone, the decompression data and induced stress critical value can be used. To quantitatively describe the overview of the fissure zone, the dip, fissure ratio and fractal need to be considered.

Coal mining safety and geology researchers in China have improved the quantitative description of the fissure zone in several ways. The results can be concluded as:

(1) Explicitly explained the laws that effects from the key stratum to the roof fissure zones. If the main key stratum is higher than the expanding range of gas flow fissures zone, then the high limit of fissure zone equals to the key stratum height, the low limit equals to the expanding range of gas flow fissure zone. If the main key stratum is unbroken and lower than the expanding range of gas flow fissure zone, the range of fissure zone is minor. If the main key 
stratum is broken and lower than the expanding range of gas flow fissure zone, the high limit of fissure zone is subkey stratum and the low limit is the gas flow fissure zone [25].

(2) Discussion on the law of development of the fissure field by the fractal method. It is difficult to estimate the progress of the development by single fractal dimension; multiple dimensions need to be applied for the estimation [15].

(3) Representation the entire progress of formation, development, inter-reaction and connection of fissures in the roof fissures zone among the mining activities. The breaking of roof rock by the mining or repeated mining activities was discovered. Thus, the distribution features of roof fissure zones spatial form were presented.

(4) Quantitative description on the fissures by MATLAB and binarization software for figure measurement and statistics. The general steps for the quantitative description using fissure maps includes: 1) Grey processing on the fissure map; 2) Estimation of the binarization threshold; 3) Measurement and statistic on the binarization fissure map [23].

The study on the quantitative description on the roof fissure zone and mining fissure zone development is now in advancing. The study is based on the deepening research of strata behaviours. However, there are still many lack of understandings, such as how to quantize and how to quantize a particular phase of fissures after the quantization method is confirmed. The development of roof fissure zone is a dynamical spatial evolution which determines that the complexity of researches on the quantitative description of roof fissure zone. Regarding to this issue, there are some deficiencies need to be improved:

(1) Most current researches only solely study the development of fissures by the aperture, quantity or fractal. The functions of each feature in the gas seepage remain unclarified due to the lack of unified studies

(2) The researches on the mechanics process and mechanism of fissure features are relatively insufficient comparing to the quantitative description.

\section{Recommendations}

According to the current study status, there are four directions of researches on the quantitative description on the roof fissure zones:

- By the drilling holes in the field locations, the gas or water flow data are collected for the studies on the development of fissures in the roof fissure zones.

- By the fractal method to run the approximate quantitative research on the development features and process of the fissures in the fissure zones.

- Researches on the features of induced stress and displacement of fissure zones by the computer numerical simulation.

- Studying on the development and distribution of fissure zones by the similarity model.

Considering the issues and the demands of the quantitative description on the roof fissure zones, the following recommendations are made:

Research on the geometry that may affect the fissures flux features. Studying on the various geometry properties of fissures which can affect the fissure flux magnitude, then finding the properties and mechanisms that making the significant influence.

Research on the distribution of roof fissure zones and the change of rock stress filed under the mining inducing. Studying the fissures which close to the geological structure, such as their formation, distribution and permeability. 
Studying on the mechanics of development of roof fissure zones and the evolutional relationship between stress and rock damage. The stress field and fissures field need to be studied under a same system of time and space so that the evolutional rule and coupling relationship of fissures field and stress field can be found.

\section{Conclusion}

Quantitative description of roof fissure zone is a complex research topic. According to large observations and studies on the mine roof fissure zones, the methods for the partition by the fissure features now are almost discovered. The development of fissure field is caused by the coupling between stress field and flux field. The main reason for the mining-induced fissure development is the mining activities.

The research status of the quantitative description of roof fissure zone is still in definition, approximate quantify and semi-quantify. The geometry and stress mechanism need deeper studies to quantitatively explain the distribution of fractures in the fissure zone, especially the geometry features of fissures which affect the flux properties and the distribution and the development mechanism of roof fissure zones. Lastly, determine the coupling relationship and evolutional rules of fissure field and stress field.

\section{Acknowledgement}

This study was financially supported by National Natural Science Foundation of China (51774319, 51574280), Chongqing Frontiers and Application-based Research Program (cstc2015jcyjBX0076), The Science and Technology Innovation Fund of China Coal Technology and Engineering Group (2015ZDXM14)).

\section{References}

[1] M. Gao, J. Xu, X. Mou, Green Technique in Coal Mining, Beijing, Journal of China University of Mining \& Technology (2003) Vol. 32, No.4. pp. 343-348.

[2] S. Li, Study on Mining-induced Fractures Field Evolution and Gas Migration Rule, Chongqing University, Chongqing, 2012.

[3] Y. Peng, Study on Evolution of Mining-induced Fractures Field and Its Coupling Effect With Gas Seepage under the Conditions of High-strength Underground Mining, China Coal Research Institute, Beijing, 2008.

[4] B. Linsky, Rock Layer and Surface Motivation in Mines, Beijing, China Coal Industry Publishing House (1989).

[5] H. Xie, H. Zhou, D. Xue, Theory, Technology and Engineering of Simultaneous Exploitation of Coal and Gas in China, Journal of China Coal Society (2014), Vol. 39, No.8, pp. 1391-1397.

[6] S. Li, H. Lin, L. Cheng, Study on Mining Overburden Rock Decompression Range and Fissure Field Feature, Datong, China Coal Society Academic Annual Meeting (2005).

[7] P. Han, Fracture Evolution Law and Gas Migration Characteristic of Overburden and Underlying Strata in Three Dimensional Mining-induced Stress Conditions, Chongqing University, Chongqing, 2015.

[8] B. Wang, Experimental Research and Numerical Simulation of Gas Migration Rule in Mininginduced Fractures Field, Chongqing University, Chongqing, 2014. 
[9] M. Qian, P. Shi, J. Xu, Control of Mining Pressure and Rock Layer, second ed., China University of Mining and Technology Press, Xuzhou, 2010.

[10] T. Liu, Influence of Mining Activities on Mine Rockmass and Control Engineering, Journey of China Coal Society (1995), Vol. 20, No.1, pp. 1-5.

[11] J. Xu, M. Gao, Study and Application of Key Stratum Theory for Control of Strata Movement, Journey of China Mining Technology University (2001), Vol. 10, No. 6, pp. 54-56.

[12] J. Xu, M. Gao, H. Jin, Study and Application of Bed Separation Distribution and Development in the Process of Strata Movement, Chinese Journal of Geotechnical Engineering (2004), Vol.26, No. 5, pp. 632-636.

[13] M. Qian, J. Xu, X. Mou, Study and Application of Key Stratum Theory for Control of Strata Movement, 21 Century China Coal Industry Fifth Member Meeting and Academic Discussion, 2001.

[14] J. Xu, M. Qian, Study and Application of Mining-induced Fracture Distribution in Green Mining, Journey of China University of Mining \& Technology (2004), Vol.33, No.2, pp. 141-149.

[15] Q. Qi, H. Li, H. Liu et.al, Mining Stress Fissure Field Spatial Evolution and Coupling with Methane Gas Flow Field, first ed., Science Press, Beijing, 2012.

[16] Y. Zhang, H. Zhang, P. Chen, Visual Exploration of Fissure Field of Overburden and Rock, Journal of China Coal Society (2008), Vol. 33, No. 11, pp. 1216-1219.

[17] Y. Zhang, Y. Kang, The Summarize and Estimation of the Development on the Exploration of overburden Failure Law, China Mining Technology (2005), Vol. 10, No. 2, pp. 10-12.

[18] Y. Zhang, F. Li, Monitoring Analysis of Fissure Development Evolution and Height of Overburden Failure of High Tension Fully-Mechanized Caving Mining, Chinses Journal of Rock Mechanics and Engineering (2011), Vol. 30, No.1, pp. 2994-3001.

[19] H. Li, W. Wang et.al, Study on Fissure Development Rule of Overlaying Strata Influenced by Mining Based on Fractal Theory, Journal of China Coal Society (2014), Vol. 39, No.6, pp. 10231030 .

[20] H. Lin, Study on the Law of Mining-induced Fracture Evolution of Overlaying Strata and Relieved Methane Delivery and Its Engineering Application in Fully-mechanized Top Coal Caving, Xi'an University of Science and Technology, Xi'an, 2009.

[21] W. Wang, Cover Stress Re-establishment and Its Permeability Evolution in Mining-induced Fracture Rock Mass, China University of Mining \& Technology, Xuzhou, 2014.

[22] M. Tu, Analysis of Mining Rock Mechanics in Relieved Drainage of Coal Bed Methane and Its Application, China University of Mining \& Technology, Xuzhou, 2008.

[23] J. Xu, Evolution Rule of Mining-induced Fracture and Its Application, first ed., China University of Mining \& Technology Press, Xuzhou, 2016.

[24] W. Li, G. Liu, T. Yao, Improvement of Methods for Crack Image Processing and Crack Feature Extraction of Expansive Soil, Rock and Soil Mechanics (2014), Vol. 35, No.12, pp. 36193626.

[25] J. Xu, X. Wang, W. Liu et.al, Effects of Primary Key Stratum Location on Height of Water Flowing Fracture Zone, Chinese Journal of Rock Mechanics and Engineering (2009), Vol.28, No.2, pp. $380-385$. 